\title{
NÍVEIS DE LISINA PARA SUÍNOS MACHOS CASTRADOS SELECIONADOS GENETICAMENTE PARA DEPOSIÇÃO DE CARNE MAGRA NA CARCAÇA, DOS 95 AOS 122 KG $^{1}$
}

\author{
Lysine nivels for Barrows with High genetic potential for lean gain from 95 to $122 \mathrm{Kg}$
}

\author{
Cláudio Luiz Corrêa Arouca², Dalton de Oliveira Fontes ${ }^{3}$, Nelson Carneiro Baião ${ }^{3}$, Martinho de Almeida e Silva ${ }^{3}$, \\ Francisco Carlos de Oliveira Silva ${ }^{4}$
}

\begin{abstract}
RESUMO
Um experimento foi realizado para se determinar as exigências de lisina de suínos machos castrados, na fase de terminação tardia, avaliando-se os efeitos de diferentes níveis de lisina da ração sobre o desempenho e características de carcaça dos animais. Utilizaram-se 50 suínos híbridos comerciais (AG-PIC 412 X C-22), com peso inicial de 95,39 $\pm 0,85 \mathrm{~kg}$ e final de 122,29 $\pm 3,02 \mathrm{~kg}$, distribuídos em delineamento experimental de blocos ao acaso, com cinco tratamentos $(0,5 ; 0,6 ; 0,7 ; 0,8$ e $0,9 \%$ de lisina total $)$, cinco repetições e dois animais por unidade experimental. Os blocos foram formados no tempo e na distribuição dos animais, dentro de cada bloco, foram adotados como critérios o parentesco e o peso inicial dos animais. Foi observado efeito quadrático dos níveis de lisina sobre o ganho de peso diário, conversão alimentar, consumo de lisina diário e taxa de deposição de carne magra diária. Não houve efeito dos tratamentos sobre o consumo de ração diário, espessura de toucinho no ponto $\mathrm{P}_{1}$, espessura de toucinho no $\mathrm{P}_{2}$, profundidade de lombo, porcentagem de carne magra, rendimento de carcaça, comprimento de carcaça pelo método brasileiro, comprimento de carcaça pelo método americano, espessura de toucinho na $10^{\mathrm{a}}$ costela, espessura de toucinho na última costela e rendimento de pernil. Concluiu-se que a exigência de lisina total para suínos machos castrados selecionados para deposição de carne magra na carcaça, de 95 a $122 \mathrm{~kg}$, é de $0,72 \%$, correspondendo a um consumo diário de $25,46 \mathrm{~g}$.
\end{abstract}

Termos para indexação: Desempenho, exigências, lisina, terminação tardia.

\begin{abstract}
An experiment was conducted to determine lysine requirements of barrows, during the late-finishing phase, to evaluate the effects of lysine levels on performance and carcass characteristics of animals. Fifty hybrid pigs (AG-PIC 412 X C-22), averaging $95.39 \pm .85 \mathrm{~kg}$ initial weight and $122.29 \pm 3.02 \mathrm{~kg}$ final weight were used in a completely randomized block design with five dietary treatments ranging from .50 to $.90 \%$ of total lysine (.10\% increments), five replicates and two animals per experimental unit. Initial body weight and relationship coefficient were used to establish the blocks. Quadratic effect of lysine level on average daily gain, feed conversion, daily lysine intake and daily lean gain was observed. There was no effect of treatments on daily feed intake, $\mathrm{P}_{1}$ backfat thickness, $\mathrm{P}_{2}$ backfat thickness, loin depth, lean percentage, carcass yield, carcass length, carcass length Brazilian method, $10^{\text {th }}$ rib fat depth, last rib fat depth and ham percentage. Based on these results, it was concluded that the total dietary lysine requirement for barrows with high genetic potential for lean gain, from 95 to $122 \mathrm{~kg}$, is $0.72 \%$ total lysine, which corresponds to approximately 25.46 g/day of lysine intake.
\end{abstract}

Index terms: Carcass, late finishing, lysine, performance, requirements, swine.

\section{(Recebido em 4 de novembro de 2005 e aprovado em 27 de março de 2006)}

\section{INTRODUÇÃO}

O peso ideal de abate de suínos tem sido determinado pela eficiência alimentar e qualidade de carcaça, sendo que nos últimos anos tem sido observado a utilização de animais mais pesados nos frigoríficos brasileiros.

Para atender o mercado consumidor as empresas de melhoramento genético têm se preocupado em produzir suínos de linhagens sintéticas que podem ser abatidos mais pesados sem afetar o desempenho, visando dessa forma maximização da produção de carne em detrimento da produção de gordura. Assim, para obtenção de progênies que apresentem carcaças magras com maior quantidade de carne, é importante a utilização de suínos híbridos comerciais de alto potencial genético de deposição de carne magra na carcaça (KILL et al., 2002a).

Suínos de elevado potencial genético para produção de carne magra necessitam de níveis mais elevados de lisina na ração, em relação aos de baixo e médio potencial, para maximizar seu desempenho e taxa de deposição de proteína na carcaça, principalmente nas fases de crescimento e terminação (FRIESEN et al., 1995). Como

'Parte da Dissertação de Mestrado do primeiro autor, financiada pelo CNPq

2Doutorando em Ciência Animal - Escola de Veterinária - Universidade Federal de Minas Gerais/UFMG - claudioarouca@yahoo.com.br

${ }^{3}$ Professor do Departamento de Zootecnia - Escola de Veterinária - Universidade Federal de Minas Gerais/UFMG.

${ }^{4}$ Pesquisador da Empresa de Pesquisa Agropecuária de Minas Gerais/EPAMIG -fcosilva@epamig,br 
primeiro aminoácido limitante em rações para suínos e diretamente responsável pela deposição de tecido muscular na carcaça o desempenho e a deposição de carne magra dos animais podem estar associados diretamente ao nível de lisina nas rações (OLIVEIRA et al., 2002a).

Neste contexto, alguns trabalhos recentes têm procurado estabelecer as exigências de lisina dessa categoria animal, visto que ainda são escassos os dados na literatura sobre exigências nutricionais de suínos com alto potencial genético para deposição de carne magra na carcaça, na fase de terminação tardia. Assim, avaliaram-se níveis de lisina para suínos machos castrados selecionados geneticamente para deposição de carne magra na carcaça, dos 95 aos $122 \mathrm{~kg}$, sobre o desempenho e características de carcaça.

\section{MATERIAL E MÉTODOS}

O experimento foi conduzido no setor de suinocultura da Fazenda Experimental Prof. Hélio Barbosa, no município de Igarapé, Minas Gerais, pertencente ao Departamento de Zootecnia da Escola de Veterinária da Universidade Federal de Minas Gerais. Utilizaram-se termômetros de máxima e mínima no interior do galpão, para registro diário da temperatura.

Foram utilizados 50 suínos machos castrados, híbridos comerciais selecionados geneticamente para elevada porcentagem de carne magra na carcaça (macho Ag-PIC 412 $\mathrm{X}$ fêmea Camborough 22), com peso inicial de 95,39 \pm 0,85 $\mathrm{kg}$, distribuídos em um delineamento experimental de blocos ao acaso, com cinco tratamentos $(0,500 ; 0,600 ; 0,700 ; 0,800$; e $0,900 \%$ de lisina total na ração), cinco repetições e dois animais por unidade experimental. $\mathrm{Na}$ distribuição dos animais, dentro de cada bloco, foram adotados como critérios o parentesco e o peso inicial dos animais.

As rações experimentais obtidas a partir de uma ração basal $\left(\mathrm{T}_{1}\right)$ que foi formulada para atender as recomendações nutricionais mínimas sugeridas pelo NRC (1998), em todos os nutrientes exceto para lisina (Tabela 1). As outras dietas experimentais foram obtidas pela suplementação da dieta basal com quatro níveis de adição de L-Lisina-HCl $(0,128$; 0,$255 ; 0,383$; e $0,510 \%$ ) em substituição ao caulim. As rações e a água foram fornecidas à vontade sendo as rações pesadas duas vezes por semana, enquanto os animais foram pesados, individualmente, no início e ao final do período experimental, para determinação do ganho de peso, conversão alimentar, consumo de ração e de lisina.

Foram feitas avaliações de carcaça "in vivo" no primeiro e último dia do período experimental, utilizando-se equipamento portátil de ultra-som $\left(\right.$ PigLog-105 ${ }^{\circledR}$ ), sendo as medidas obtidas sempre do lado esquerdo do animal. Foram medidas as Espessuras de Toucinho no Ponto $\mathrm{P}_{1}$ $\left(\right.$ ETP $\left._{1}\right)$, obtida a $6,5 \mathrm{~cm}$ da linha dorso-lombar e a $6,5 \mathrm{~cm}$ da última costela na direção caudal; no Ponto $P_{2}\left(\mathrm{ETP}_{2}\right)$, obtida a $6,5 \mathrm{~cm}$ da linha dorso-lombar e a $6,5 \mathrm{~cm}$ da última costela na direção cranial; a profundidade de lombo (PL); a Porcentagem de carne magra (PCM), utilizando-se como preditores a espessura de toucinho (nos pontos $\mathrm{P}_{1}$ e $\mathrm{P}_{2}$ ) e a profundidade de lombo; e a Taxa de deposição de carne magra diária (TDCMD), relação entre a porcentagem de carne magra estimada no último dia e a porcentagem de carne magra no primeiro dia pelo número de dias em experimento.

Ao final do período experimental, quando os animais atingiram $122,29 \pm 3,02 \mathrm{~kg}$, foram abatidos em frigorífico comercial após jejum de 10 horas. As carcaças foram armazenadas por 16 a 20 horas em câmara fria, à temperatura de 2 a $4^{\circ} \mathrm{C}$, e em seguida foram efetuadas as avaliações de carcaça. Foram obtidos: o Rendimento de carcaça $(R C)$, relação entre o peso da carcaça quente e o peso vivo do animal; o Peso da carcaça fria, obtido após o período na câmara fria; o Comprimento de carcaça pelo Método Brasileiro de Classificação de Carcaça $(C C M B)$, medição do bordo cranial da sínfise pubiana ao bordo crânio-ventral do atlas; Comprimento de carcaça pelo Método Americano de Classificação de Carcaça (CCMA), medição do bordo cranial da sínfise pubiana ao bordo crânio-ventral da primeira costela; Espessura de toucinho (ET), obtidas com régua milimetrada, após dissecação da camada de gordura; Espessura de toucinho na $10^{a}$ costela $\left(E T-10^{a}\right)$, tomada entre a $10^{\mathrm{a}}$ e $11^{\mathrm{a}}$ costela a $6,5 \mathrm{~cm}$ da linha dorso-lombar; Espessura de toucinho na última costela (ETUL), tomada na altura da interseção da última vértebra torácica com a primeira lombar, perpendicularmente à linha dorso-lombar a 6,5 cm da mesma; Cortes cárneos da carcaça, após as medições, as carcaças foram desossadas em cortes de acordo com os procedimentos padrões do frigorífico, sendo calculado o Rendimento de pernil $(R P)$, relação entre o peso do pernil e o peso da carcaça resfriada.

Os dados de desempenho, das medidas ultrasônicas in vivo e das características de carcaça foram submetidos à análise de variância utilizando-se o SAEG Sistemas de Análises Estatísticas e Genéticas (SAEG, 2000). Para os resultados das medidas ultra-sônicas in vivo utilizou-se como covariável o resultado correspondente à mesma variável no início do experimento e para estimar a exigência de lisina utilizou-se o modelo de regressão quadrático. 
TABELA 1 - Composição percentual e calculada das rações experimentais.

\begin{tabular}{|c|c|c|c|c|c|}
\hline \multirow[b]{2}{*}{ Ingredientes } & \multicolumn{5}{|c|}{ Nível de lisina na ração (\%) } \\
\hline & $\mathbf{0 , 5 0 0}$ & $\mathbf{0 , 6 0 0}$ & 0,700 & $\mathbf{0 , 8 0 0}$ & 0,900 \\
\hline Milho grão & 83,270 & 83,270 & 83,270 & 83,270 & 83,270 \\
\hline Farelo de soja & 9,200 & 9,200 & 9,200 & 9,200 & 9,200 \\
\hline Glúten de milho & 3,640 & 3,640 & 3,640 & 3,640 & 3,640 \\
\hline Fosfato bicálcico & 1,140 & 1,140 & 1,140 & 1,140 & 1,140 \\
\hline Calcário calcítico & 1,000 & 1,000 & 1,000 & 1,000 & 1,000 \\
\hline Sal comum & 0,350 & 0,350 & 0,350 & 0,350 & 0,350 \\
\hline Antibiótico & 0,200 & 0,200 & 0,200 & 0,200 & 0,200 \\
\hline Premix vitamínico ${ }^{1}$ & 0,300 & 0,300 & 0,300 & 0,300 & 0,300 \\
\hline Premix mineral $^{2}$ & 0,100 & 0,100 & 0,100 & 0,100 & 0,100 \\
\hline Caulim (Inerte) & 0,800 & 0,672 & 0,545 & 0,417 & 0,290 \\
\hline L-Lisina $\mathrm{HCl}(78,4 \%)$ & --- & 0,128 & 0,255 & 0,383 & 0,510 \\
\hline Total & 100,0 & 100,0 & 100,0 & 100,0 & 100,0 \\
\hline \multicolumn{6}{|c|}{ Valores nutricionais calculados (\% na MN) } \\
\hline Energia metabolizável (kcal/kg) & 3204 & 3204 & 3204 & 3204 & 3204 \\
\hline Proteína bruta $(\%)$ & 13,5 & 13,5 & 13,5 & 13,5 & 13,5 \\
\hline Cálcio (\%) & 0,700 & 0,700 & 0,700 & 0,700 & 0,700 \\
\hline Fósforo disponível (\%) & 0,300 & 0,300 & 0,300 & 0,300 & 0,300 \\
\hline Lisina Total $(\%)$ & 0,500 & 0,600 & 0,700 & 0,800 & 0,900 \\
\hline
\end{tabular}

${ }^{1}$ Níveis de garantia (por kg do produto) Guaranteed levels ( $\mathrm{kg}$ of product): ácido fólico (folic acid), 116,55 mg; ácido pantotênico (pantothenic acid), 2.333,5 mg; biotina (biotin), 5,28 mg; niacina (niacin), $5.600 \mathrm{mg}$; piridoxina (pyridoxine), $175 \mathrm{mg}$; riboflavina (riboflavin), 933,3 mg; tiamina (thiamin), $175 \mathrm{mg}$; vitamina A (vitamin A), 1.225.000 U.I.; vitamina $\mathrm{D}_{3}$ (vitamin $D_{3}$ ), 315.000 U.I.; vitamina $\mathrm{E}$ (vitamin $E$ ), $1.400 \mathrm{mg}$; vitamina $\mathrm{K}_{3}$ (vitamin $K_{3}$ ), $700 \mathrm{mg}$; vitamina $\mathrm{B}_{12}($ vitamin $B_{12}$ ), $6.825 \mathrm{mcg}$; selênio (selenium), $105 \mathrm{mg}$; antioxidante (antioxidant) $1.500 \mathrm{mg}$;

${ }^{2}$ Níveis de garantia (por kg do produto) Guaranteed levels ( $\mathrm{kg}$ of product): cálcio (calcium), $98.800 \mathrm{mg}$; cobalto (cobalt), $185 \mathrm{mg}$; cobre (copper), $15.750 \mathrm{mg}$; ferro (iron), $26.250 \mathrm{mg}$; iodo(iodine), $1.470 \mathrm{mg}$; manganês (manganese), $41.850 \mathrm{mg}$; zinco (zinc), $77.999 \mathrm{mg}$.

\section{RESULTADOS E DISCUSSÃO}

As temperaturas mínimas e máximas verificadas no período foram, respectivamente, $12,98 \pm 2,37^{\circ} \mathrm{C}$ e $27,75 \pm$ $3,26^{\circ} \mathrm{C}$.

Os resultados de consumo de ração, consumo de lisina, ganho de peso e conversão alimentar de suínos machos castrados na fase de terminação tardia encontramse na Tabela 2.

O consumo de ração diário (CRD) não foi influenciado $(\mathrm{P}>0,10)$ pelos níveis de lisina da ração. Resultados semelhantes foram obtidos por Cline et al. (2000), Dourmad et al. (1996), Friesen et al. (1994b, 1995), Hahn et al. (1995) e Loughmiller et al. (1998), que também utilizaram suínos na fase de terminação tardia. Entretanto, Bertol et al. (2000) e Oliveira et al. (2001, 2002a) relataram diminuição linear no CRD de suínos machos castrados com o aumento na concentração de lisina na ração.

O consumo de lisina diário elevou-se de modo quadrático $(\mathrm{P}<0,02)$ com o aumento dos níveis de lisina da ração, conforme equação $v=-10,5067+67,6535 X-24,5786$ $\mathrm{X}^{2},\left(\mathrm{R}^{2}=0,99\right)$. Uma vez que não foi observado aumento significativo no CRD entre os tratamentos pode-se inferir que o aumento do consumo de lisina ocorreu em função do aumento dos níveis de lisina da ração. Bertol et al. (2000), Cline et al. (2000), Loughmiller et al. (1998) e Oliveira et al. (2001, 2002a), trabalhando com suínos na fase de terminação tardia também observaram aumento no consumo de lisina em função do aumento de lisina da ração.

Observou-se efeito quadrático $(\mathrm{P}<0,02)$ dos níveis de lisina da ração sobre o ganho de peso diário (GPD), que 
aumentou até o nível de $0,71 \%$ de lisina total $(0,222 \%$ / Mcal de EM), o que correspondeu a um consumo de lisina de 25,14 g/dia (Figura 1). Resultados semelhantes foram obtidos por Hahn et al. (1995) avaliando níveis de lisina digestível $(0,41$ a $0,63 \%)$ para suínos híbridos, machos castrados e fêmeas de 90 a $110 \mathrm{~kg}$, e por Friesen et al. (1995) avaliando efeito dos níveis de lisina digestível $(0,44$ a $0,94 \%)$ sobre o GPD de leitoas com alto potencial para deposição de carne magra, dos 72 aos $136 \mathrm{~kg}$.

Por outro lado, Loughmiller et al. (1998) e Oliveira et al. (2001, 2002a) não observaram efeito significativo dos níveis de lisina sobre o ganho de peso de suínos na fase de terminação tardia, enquanto Bertol et al. (2000), avaliando níveis de lisina digestível entre 0,60 e 0,90\% em suínos machos castrados de 80 a $120 \mathrm{~kg}$, verificaram decréscimo linear no GPD dos animais.

Observou-se efeito quadrático $(\mathrm{P}<0,02)$ dos níveis de lisina sobre a conversão alimentar (Figura 2), que melhorou até o nível de $0,72 \%$ de lisina total (0,225\%/Mcal de EM), correspondendo a um consumo estimado de 25,46 g de lisina por dia. O nível estimado de lisina total está próximo ao resultado encontrado por Oliveira et al. (2001), que avaliando os efeitos de níveis crescentes de lisina $(0,50$ a $0,90 \%)$ sobre o desempenho de suínos machos castrados com alto potencial genético para deposição de carne magra, dos 95 aos $110 \mathrm{~kg}$ estimaram em $0,76 \%$ a exigência de lisina total destes animais.

Entretanto, Oliveira et al. (2002a) obtiveram resultados superiores estimando em $0,80 \%$ a exigência de lisina total para suínos machos castrados de alto potencial genético, de 110 a $125 \mathrm{~kg}$. Porém, o valor de exigência expresso em gramas de lisina total (23,9 g/dia) obtido por Oliveira et al. (2002a) foi inferior ao obtido neste trabalho $(25,46 \mathrm{~g} / \mathrm{dia})$, corroborando os relatos de Friesen et al. (1994b) de que as exigências de nutrientes deveriam ser expressas na base de gramas ingeridas por dia para otimizar o desempenho e qualidade de carcaça. Além disso, sabese que a ingestão de lisina total exigida pelo suíno depende do apetite ou do potencial de ingestão de alimento, da taxa de deposição de carne magra e da eficiência desta deposição, o que poderia explicar as diferenças observadas (HAHN et al., 1995).

O melhor nível de lisina total $(0,72 \%)$ estimado neste estudo foi $20 \%$ superior àquele preconizado pelo NRC (1998) para suínos machos castrados de 80 a 120 kg, que é de $0,60 \%$ de lisina total e por àqueles recomendados por Friesen et al. (1994b), que trabalhando com machos castrados híbridos, em terminação tardia, estimaram em $0,56 \%$ de lisina total o nível que proporcionou o melhor resultado de conversão alimentar. Assim, podemos deduzir que, quando comparados a outros grupos de menor mérito genético, suínos de elevado potencial para deposição de tecido magro exigem maiores quantidades de lisina na ração para expressar sua maior eficiência produtiva, respondendo favoravelmente ao aumento de lisina.

Suínos machos castrados na fase de terminação tardia com alta capacidade de deposição de carne na carcaça apresentam menor capacidade de consumo de alimento, entretanto, são mais eficientes, em relação a suínos de baixo potencial genético, o que explicaria a elevada exigência de lisina desses grupos genéticos (FRIESEN et al., 1994a).

TABELA 2 - Efeito do nível de lisina da ração sobre o ganho de peso diário (GPD), consumo de ração diário (CRD), conversão alimentar (CA) e consumo de lisina diário (CLD).

\begin{tabular}{lccccccc}
\hline \multirow{2}{*}{ Parâmetros } & \multicolumn{5}{c}{ Nível de lisina da ração $(\%)$} & CV \\
\cline { 2 - 6 } & $\mathbf{0 , 5 0 0}$ & $\mathbf{0 , 6 0 0}$ & $\mathbf{0 , 7 0 0}$ & $\mathbf{0 , 8 0 0}$ & $\mathbf{0 , 9 0 0}$ & $(\boldsymbol{\%})$ \\
\hline Consumo de ração diário $(\mathrm{g})_{\text {Consumo de lisina diário }^{1}(\mathrm{~g})}$ & 3487 & 3467 & 3508 & 3582 & 3348 & 7,65 \\
Ganho de peso diário $^{2}(\mathrm{~g})$ & 17,44 & 20,80 & 24,56 & 28,66 & 30,13 & 7,31 \\
Conversão alimentar $^{3}(\mathrm{~g} / \mathrm{g})$ & 934 & 1065 & 1090 & 1058 & 962 & 11,30 \\
\hline
\end{tabular}

${ }^{1}$ Efeito quadrático $(\mathrm{P}<0,02)-\mathrm{v}=-10,5067+67,6535 \mathrm{X}-24,5786 \mathrm{X}^{2}\left(\mathrm{R}^{2}=0,99\right)$.

${ }^{2}$ Efeito Efeito quadrático $(\mathrm{P}<0,02)-\mathrm{v}=-728,663+5159,14 \mathrm{X}-3648,98 \mathrm{X}^{2}\left(\mathrm{R}^{2}=0,99\right)$.

${ }^{3}$ Efeito Efeito quadrático $(\mathrm{P}<0,02)-\mathrm{v}=8,32638-14,0508 \mathrm{X}+9,70242 \mathrm{X}^{2} \quad\left(\mathrm{R}^{2}=0,84\right)$. 


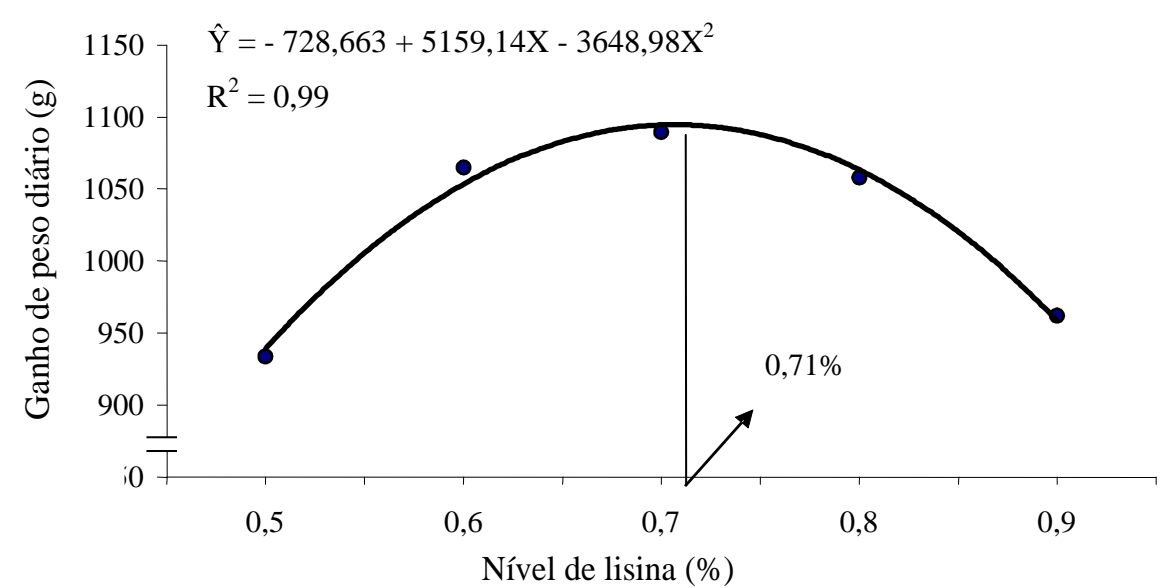

FIGURA 1 - Efeito do nível de lisina da ração sobre o ganho de peso diário.

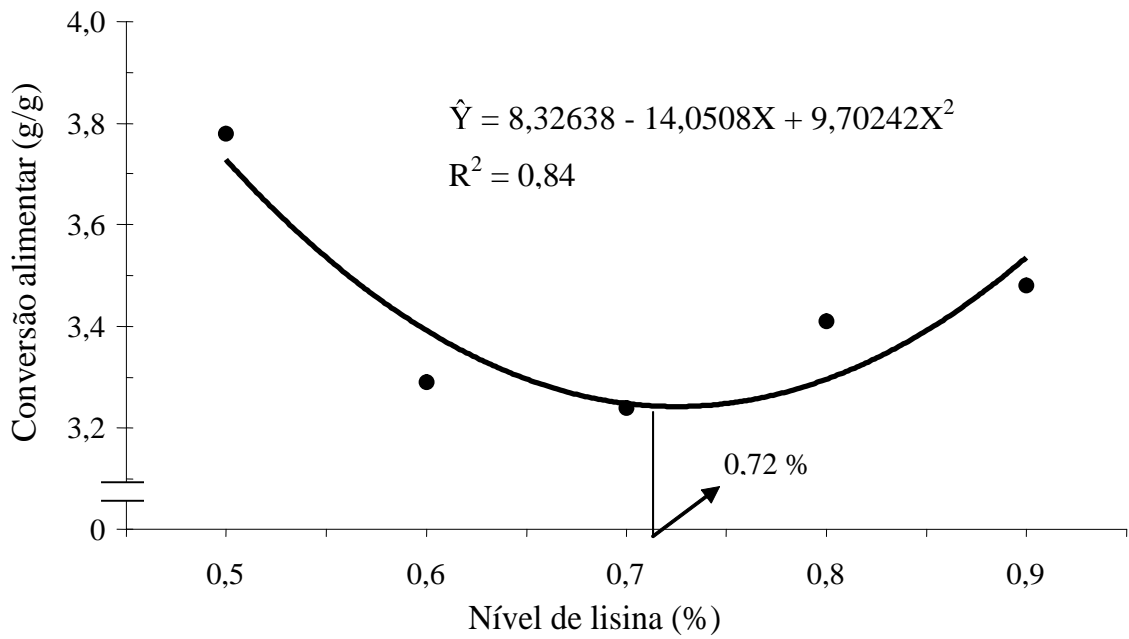

FIGURA 2 - Efeito do nível de lisina da ração sobre a conversão alimentar.

Os resultados de espessura de toucinho, profundidade de lombo, porcentagem de carne magra e taxa de deposição de carne magra diária de suínos machos castrados em terminação tardia consumindo diferentes níveis de lisina encontram-se na Tabela 3.

Não houve efeito $(\mathrm{P}>0,10)$ dos níveis de lisina da ração sobre a espessura de toucinho no ponto $\mathrm{P}_{1}\left(\mathrm{ETP}_{1}\right)$, espessura de toucinho no ponto $\mathrm{P}_{2}\left(\mathrm{ETP}_{2}\right)$ e a profundidade de lombo (PL), medidas por ultra-som. Resultados semelhantes foram obtidos por Loughmiller et al. (1998) e Moreira et al. $(2001,2002)$ que, trabalhando com níveis de lisina para suínos machos castrados nas fases de crescimento, terminação e marrãs em terminação tardia, respectivamente, não observaram efeito significativo dos níveis de lisina sobre a ET (medida com ultra-som na $10^{\mathrm{a}}$ costela). No entanto, Gasparotto et al. (2001), avaliando níveis de lisina entre 0,75 e 1,20\% para suínos machos castrados de dois grupos genéticos na fase de crescimento, observaram redução linear sobre a ETP 1 e PL para os animais do grupo genético melhorado.

Não foi observado efeito $(\mathrm{P}>0,10)$ dos tratamentos sobre a porcentagem de carne magra (PCM). Oliveira et al. 
(2002b) e Souza Filho et al. (2000) que utilizaram machos castrados na fase de terminação tardia e Kill et al. (2002a,b) trabalhando com fêmeas, também não observaram efeito dos níveis de lisina da ração sobre o rendimento de carne magra. Entretanto, Cline et al. (2000) e Loughmiller et al. (1998) observaram que PCM aumentou de modo linear em função dos níveis de lisina utilizando leitoas em terminação tardia.

De maneira semelhante ao consumo estimado de lisina, a PCM média $(55,83 \%)$ foi superior ao valor médio relatado $(53,75 \%)$ por Oliveira et al. (2002b). Essa diferença de $2,08 \%$ de PCM na carcaça pode explicar o aumento na exigência de lisina de 1,56 g/dia, ocorrida entre os trabalhos. De acordo com Ellis (1998), a taxa de deposição de tecido magro apresentada pelo suíno determinará suas exigências para proteína e lisina e o seu consumo máximo voluntário determinará a concentração dietética de nutrientes necessária para satisfazer as exigências. Esses resultados corroboram que a composição do ganho pode ser alterada para maior deposição de proteína e menor deposição de lipídeos, à medida que o nível de lisina da ração é aumentado.

Observou-se efeito quadrático $(\mathrm{P}<0,03)$ dos tratamentos sobre a taxa de deposição de carne magra diária (TDCMD), que aumentou até o nível de $0,73 \%$ $(0,228 \%$ /Mcal de EM) de lisina total, correspondendo a um consumo de lisina total estimado de 25,78 g/dia (Figura 3). Hahn et al. (1995), avaliando os efeitos de níveis de lisina sobre características de carcaça de suínos em terminação tardia, também observaram efeito quadrático sobre a TDCMD.

Os resultados de rendimento de carcaça, comprimento de carcaça pelo método brasileiro e pelo método americano, espessura de toucinho na $10^{\mathrm{a}}$ costela, espessura de toucinho na última costela e rendimento de pernil de suínos machos castrados consumindo diferentes níveis de lisina e abatidos aos $122 \mathrm{~kg}$ encontram-se na Tabela 4.

Não foi observado efeito $(\mathrm{P}>0,10)$ dos níveis de lisina sobre o rendimento de carcaça (RC), comprimento de carcaça pelo método brasileiro (CCMB) ou comprimento de carcaça pelo método americano (CCMA). Do mesmo modo, Friesen et al. (1994b, 1995), Kill et al. (2002a, b), Oliveira et al. (2002b) e Souza Filho et al. (2000), avaliando níveis de lisina da dieta sobre as características de carcaça de suínos na fase de terminação tardia, não observaram efeitos significativo dos tratamentos sobre essas variáveis.

Entretanto, Cline et al. (2000), utilizando fêmeas de 54 a $116 \mathrm{~kg}$, observaram diminuição linear do rendimento de carcaça, enquanto Gonçalves et al. (1999), com machos castrados e fêmeas, dos 60 aos $112 \mathrm{~kg}$, observaram aumento no RC e diminuição do CCMB com a elevação do nível de lisina das rações.

A espessura de toucinho ET-10 ${ }^{\mathrm{a}}$ e ETUL não foram afetadas $(\mathrm{P}>0,10)$ pelos níveis de lisina da ração. Friesen et al. (1994b), Hahn et al. (1995), Kill et al. (2002a,b), Oliveira et al. (2002b) e Souza Filho et al. (2000), também não observaram efeito dos níveis de lisina sobre a espessura de toucinho de suínos em terminação tardia. Entretanto, Friesen et al. (1995) observaram aumento quadrático da ET, enquanto Cline et al. (2000) observaram diminuição linear quando utilizaram fêmeas suínas em terminação tardia.

TABELA 3 - Efeito do nível de lisina da ração sobre as medidas de espessura de toucinho no ponto $\mathrm{P}_{1}\left(\mathrm{ETP}_{1}\right)$, espessura de toucinho no ponto $\mathrm{P}_{2}\left(\mathrm{ETP}_{2}\right)$, profundidade de lombo $(\mathrm{PL})$, porcentagem de carne magra $(\mathrm{PCM})$ e taxa de deposição de carne magra diária (TDCMD), obtidas in vivo.

\begin{tabular}{lcccccc}
\hline \multirow{2}{*}{\multicolumn{1}{c}{ Parâmetros }} & \multicolumn{9}{c}{ Nível de lisina da ração $(\%)$} & CV \\
\cline { 2 - 6 } & $\mathbf{0 , 5 0 0}$ & $\mathbf{0 , 6 0 0}$ & $\mathbf{0 , 7 0 0}$ & $\mathbf{0 , 8 0 0}$ & $\mathbf{0 , 9 0 0}$ & $(\%)$ \\
\hline $\mathrm{ETP}_{1}(\mathrm{~mm})$ & 14,40 & 15,30 & 15,44 & 13,80 & 14,78 & 13,10 \\
$\mathrm{ETP}_{2}(\mathrm{~mm})$ & 16,70 & 18,40 & 18,11 & 17,10 & 18,00 & 10,85 \\
Profundidade de Lombo (mm) & 58,10 & 56,71 & 57,57 & 56,00 & 58,00 & 5,14 \\
Porcentagem de Carne Magra (\%) & 56,51 & 54,76 & 55,70 & 56,37 & 55,81 & 2,30 \\
$\mathrm{TDCMD}^{1}$ (g/dia) & 375 & 461 & 489 & 472 & 439 & 21,91 \\
\hline
\end{tabular}

${ }^{1}$ Efeito quadrático $(\mathrm{P}<0,03)-\mathrm{v}=-606,783+2989,31 \mathrm{X}-2036,40 \mathrm{X}^{2}\left(\mathrm{R}^{2}=0,98\right)$. 


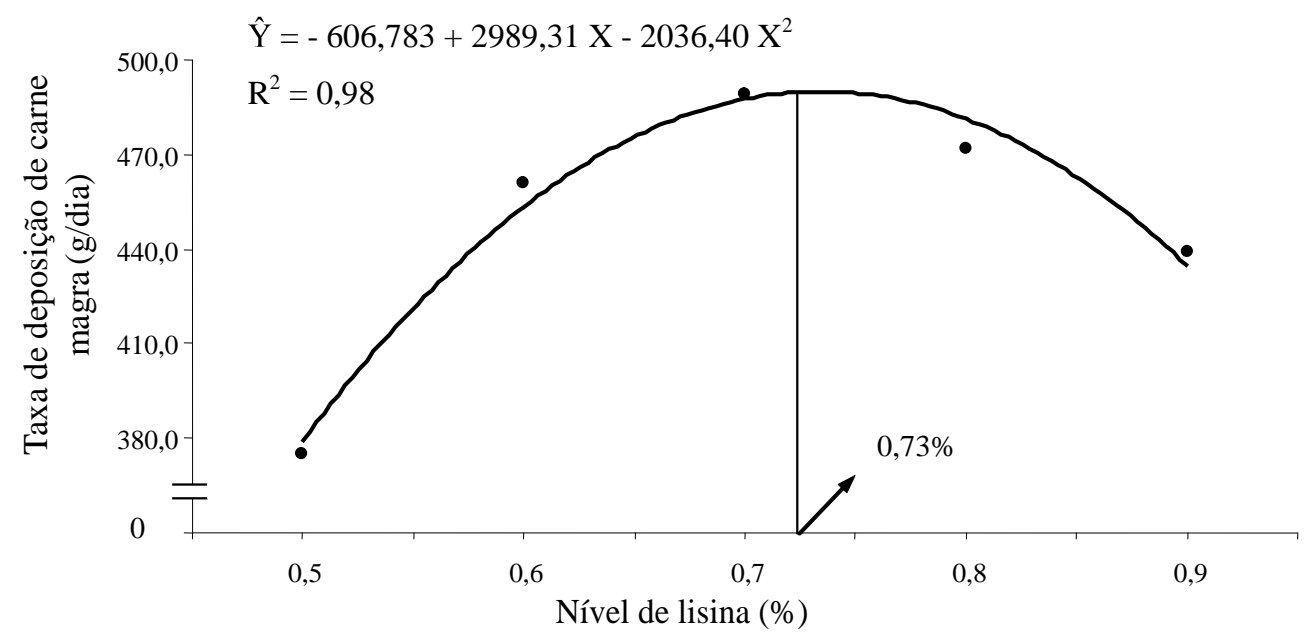

FIGURA 3 - Efeito do nível de lisina da ração sobre a taxa de deposição de carne magra diária.

TABELA 4 - Efeito do nível de lisina da ração sobre o rendimento de carcaça (RC), comprimento de carcaça pelo método brasileiro (CCMB), comprimento de carcaça pelo método americano (CCMA), espessura de toucinho na $10^{\mathrm{a}}$ costela $\left(\mathrm{ET}-10^{\mathrm{a}}\right)$, espessura de toucinho na última costela (ETUL) e rendimento de pernil (RP).

\begin{tabular}{lcccccc}
\hline \multirow{2}{*}{\multicolumn{1}{c}{ Parâmetros }} & \multicolumn{7}{c}{ Nível de lisina da ração (\%) } & CV \\
\cline { 2 - 6 } & $\mathbf{0 , 5 0 0}$ & $\mathbf{0 , 6 0 0}$ & $\mathbf{0 , 7 0 0}$ & $\mathbf{0 , 8 0 0}$ & $\mathbf{0 , 9 0 0}$ & $(\%)$ \\
\hline Rendimento de carcaça (\%) & 80,03 & 79,49 & 80,25 & 79,86 & 81,00 & 2,70 \\
CCMB (cm) & 102,63 & 101,15 & 102,22 & 100,56 & 101,86 & 3,65 \\
CCMA (cm) & 86,94 & 85,75 & 86,78 & 85,94 & 86,07 & 3,87 \\
ET-10 $(\mathrm{mm})$ & 16,75 & 19,50 & 18,67 & 17,38 & 17,57 & 17,82 \\
ETUL $(\mathrm{mm})$ & 12,63 & 16,00 & 13,56 & 13,38 & 14,00 & 21,95 \\
Rendimento de pernil (\%) & 24,58 & 24,05 & 24,20 & 24,26 & 23,48 & 5,64 \\
\hline
\end{tabular}

Não se observou efeito $(\mathrm{P}>0,10)$ dos níveis de lisina sobre o rendimento de pernil (RP). Resultados semelhantes foram verificados por Gonçalves et al. (1999), Oliveira et al. (2002b) e Souza Filho et al. (2000), utilizando suínos machos castrados, na fase de terminação tardia. Kill et al. (2002a,b), também não observaram efeito significativo dos tratamentos sobre o RP, trabalhando com fêmeas, na fase de terminação tardia.

$\mathrm{O}$ valor médio de RP de $24,11 \%$ foi inferior àqueles encontrados por Oliveira et al. (2002b) e Souza Filho et al. (2000) que relataram valores de 26,96 e 29,18\%, respectivamente, utilizando machos castrados. Com fêmeas, Kill et al. (2002a,b), observaram respectivamente, 32,18 e $32,83 \%$ de RP. Provavelmente, essas diferenças foram devidas às diferentes metodologias utilizadas na obtenção do corte, uma vez que no presente trabalho o pernil foi obtido de acordo com o procedimento padrão do frigorífico.

\section{CONCLUSÕES}

A exigência de lisina de suínos machos castrados selecionados geneticamente para deposição de carne magra na carcaça, de 95 a $122 \mathrm{~kg}$, é de $0,72 \%$ de lisina total $(0,225 \% /$ Mcal de EM), correspondendo a um consumo estimado de 25,46 g de lisina total por dia.

\section{AGRADECIMENTOS}

À Agroceres Nutrição Animal e Agroceres - Pic pela cooperação e apoio. 


\section{REFERÊNCIAS BIBLIOGRÁFICAS}

BERTOL, T. M.; LUDKE, J. V.; FRAIHA, M. Determinação das exigências de lisina digestível para suínos machos castrados e fêmeas dos 80 aos $120 \mathrm{~kg}$ de peso vivo. In: REUNIÃO ANUAL DA SOCIEDADE BRASILEIRA DE ZOOTECNIA, 37., 2000, Viçosa. Anais...Viçosa: SBZ, 2000. CD-ROM.

CLINE, T. R.; CROMWELL, G. L.; CRENSHAW, T. D. Further assessment of the dietary lysine requirement of finishing gilts. Journal of Animal Science, Champaign, v. 78, n. 4, p. 987-992, 2000.

DOURMAD, J. Y.; GUILLOU, D.; SÈVE, B. Response to dietary lysine supply during the finishing period in pigs. Livestock Production Science, Amsterdam, v. 45, n. 2/3, p. 179-186, 1996.

ELLIS, M. Efeitos do melhoramento genético, sexo, regime alimentar e peso de abate sobre o rendimento de carne magra na carcaça. In: SIMPÓSIO SOBRE RENDIMENTO E QUALIDADE DA CARNE SUÍNA, 1., 1998, Concórdia. Anais... Concórdia: Embrapa-CNPSA, 1998. p. 52-79.

FRIESEN, K. G.; NELSSEN, J. L.; GOODBAND, R. D. Influence of dietary lysine on growth and carcass composition of high-lean-growth gilts fed from 34 to 72 kilograms. Journal of Animal Science, Champaign, v. 72, n. 7, p. 1761-1770, 1994a.

FRIESEN, K. G.; NELSSEN, J. L.; GOODBAND, R. D. The effect of dietary lysine on growth, carcass composition, and lipid metabolism in high-lean growth gilts fed from 72 to 136 kilograms. Journal of Animal Science, Champaign, v. 73, n. 11, p. 3392-3401, 1995.

FRIESEN, K. G.; NELSSEN, J. L.; UNRUH, R. D. Effects of the interrelationship between genotype, sex, and dietary lysine on growth performance and carcass composition in finishing pigs fed to either 104 or 127 kilograms. Journal of Animal Science, Champaign, v. 72, n. 4, p. 946-954, 1994 b.

GASPAROTTO, L. F; MOREIRA, I.; FURLAN, A. C. Exigência de lisina, com base no conceito de proteína ideal, para suínos machos castrados de dois grupos genéticos, na fase de crescimento. Revista da Sociedade Brasileira de Zootecnia, Viçosa, v. 30, n. 6, p. 1742-1749, 2001.
GONÇALVES, T. M.; BERTECHINI, A. G.; KONING, G. de. Lisina, energia, sexo e períodos experimentais em características de carcaça de suínos híbridos. In: CONGRESSO BRASILEIRO DE VETERINÁRIOS ESPECIALISTAS EM SUÍNOS, 9., 1999, Belo Horizonte. Anais... Belo Horizonte: ABRAVES, 1999. p. 453-455.

HAHN, J. D.; BIEHL, R. R.; BAKER, D. H. Ideal digestible lysine level for early and late-finishing swine. Journal of Animal Science, Champaign, v. 73, n. 3, p. 773-784, 1995.

KILL, J. L.; DONZELE, J. L.; FERREIRA, A. S. Efeito de planos de nutrição sobre as características de carcaça e rendimento de carne de leitoas com elevado potencial genético, abatidas aos $105 \mathrm{~kg}$. In: REUNIÃO ANUAL DA SOCIEDADE BRASILEIRA DE ZOOTECNIA, 39., 2002, Recife. Anais... Recife: SBZ, 2002a. CD-ROM.

KILL, J. L.; DONZELE, J. L.; SILVA, M. V. G. B. Efeito de planos de nutrição sobre as características de carcaça de leitoas com elevado potencial genético, abatidas aos 115 kg. In: REUNIÃOANUAL DA SOCIEDADE BRASILEIRA DE ZOOTECNIA, 39., 2002, Recife. Anais... Recife: SBZ, 2002b. CD-ROM.

LOUGHMILLER, J. A.; NELSSEN, J. L.; GOODBAND, R. D. Influence of dietary lysine on growth performance and carcass characteristics of late-finishing gilts. Journal of Animal Science, Champaign, v. 76, n. 4, p. 1075-1080, 1998.

MOREIRA, I.; GASPAROTTO, L. F.; FURLAN, A. C. Exigência de lisina para machos castrados de dois grupos genéticos de suínos na fase de terminação, com base no conceito de proteína ideal. Revista da Sociedade Brasileira de Zootecnia, Viçosa, v. 31, n. 1, p. 96-103, 2002.

MOREIRA, I.; KUTSCHENKO, M.; FURLAN, A. C. Exigência de lisina para suínos em crescimento, alimentados com baixo teor de proteína, baseado no conceito de proteína ideal. In: REUNIÃO ANUAL DA SOCIEDADE BRASILEIRA DE ZOOTECNIA, 38., 2001, Piracicaba. Anais... Piracicaba: SBZ, 2001. CD-ROM.

NATIONAL RESOURCE COUNCIL. Nutrient requirements of swine. 10. ed. Washington, 1998. 189 p.

Ciênc. agrotec., Lavras, v. 31, n. 2, p. 531-539, mar./abr., 2007 
OLIVEIRA, A. L. S.; DONZELE, J. L.; OLIVEIRA, R. F. M. Níveis de lisina para suínos machos castrados de alto potencial genético para deposição de carne magra dos 95 aos $110 \mathrm{~kg}$. In: REUNIÃO ANUAL DA SOCIEDADE BRASILEIRA DE ZOOTECNIA, 38., 2001, Piracicaba. Anais... Piracicaba: SBZ, 2001. CD-ROM.

OLIVEIRA, A. L. S.; DONZELE, J. L.; OLIVEIRA, R. F. M. Lisina para suínos machos castrados de alto potencial genético para deposição de carne magra dos 110 aos $125 \mathrm{~kg}$ : I. efeito sobre o desempenho. In: REUNIÃO ANUAL DA SOCIEDADE BRASILEIRA DE ZOOTECNIA, 39., 2002, Recife. Anais... Recife: SBZ, 2002a. CD-ROM.
OLIVEIRA, A. L. S.; DONZELE, J. L.; OLIVEIRA, R. F. M. Lisina para suínos machos castrados de alto potencial genético para deposição de carne magra dos 110 aos $125 \mathrm{~kg}$ : II. efeito sobre as características de carcaça. In: REUNIÃO ANUAL DA SOCIEDADE BRASILEIRA DE ZOOTECNIA, 39., 2002, Recife. Anais... Recife: SBZ, 2002b. CD-ROM.

SISTEMAS DEANÁLISES ESTATÍSTICAS E GENÉTICA. SAEG. Versão 8.0. Viçosa: UFV, 2000.

SOUZA FILHO, G. A.; LIMA, J. A. F.; FIALHO, E. T. Efeito de planos de nutrição e de genótipos sobre características físicas de carcaça de suínos. Ciência e Agrotecnologia, Lavras, v. 24, n. 4, p. 1060-1067, 2000. 